\title{
Does neurological recovery in thoracolumbar and lumbar burst fractures depend on the extent of canal compromise?
}

\author{
SP Mohanty*,1 and N Venkatram ${ }^{1}$ \\ ${ }^{1}$ Department of Orthopaedics, Kasturba Hospital, Manipal, India
}

\begin{abstract}
Study design: Prospective study.
Objectives: Forty-five consecutive cases of thoracolumbar and lumbar burst fractures treated non-operatively were analyzed to correlate the extent of canal compromise at the time of injury with (i) the initial neurologic deficit and (ii) with the extent of neurological recovery at 1 year. The effect of spinal canal remodeling on neurological recovery was also analyzed.

Setting: University teaching hospital in south India.

Methods: The degree of spinal canal compromise and canal remodeling were assessed from computed tomography scans. The neurologic status was assessed by Frankel's grading.

Results: The mean canal compromise in patients with neurologic deficit was $46.2 \%$ while in patients with no neurological deficit it was $36.3 \%$. The mean spinal canal compromise in patients with neurological recovery was $46.1 \%$ and $48.4 \%$ in those with no recovery. The amount of canal remodeling in patients who recovered was $51.7 \%$ and $46.1 \%$ in the patients who did not recover. None of these differences was statistically significant.

Conclusion: This study shows that there is no correlation between the neurologic deficit and subsequent recovery with the extent of spinal canal compromise in thoracolumbar burst fractures.
\end{abstract}

Spinal Cord (2002) 40, 295-299. doi:10.1038/sj.sc.3101283

Keywords: spinal injuries; burst fractures; neurological deficit; canal compromise; canal remodeling

\section{Introduction}

Most burst fractures of the spine are associated with retropulsion of bony fragments into the spinal canal. The clinical significance of bony encroachment of the canal with reference to neurological outcome is not clear.

Consequently, the role of surgery in the treatment of these fractures is controversial. Some surgeons advocate surgical treatment with a view of restoring the spinal canal and stabilizing the spine, ${ }^{1,2}$ while others recommend non-operative treatment. ${ }^{3-5}$ Some reports suggest that although surgical removal of bony fragments may restore the spinal canal, it does not improve the chance of neurological recovery. ${ }^{6-8}$

This study was undertaken to determine whether neurological damage and subsequent neurological

*Correspondence: SP Mohanty, Department of Orthopaedics, Division of Spinal Surgery, Kasturba Hospital, Manipal, India576119. recovery following burst fractures of the thoracolumbar spine depend on the extent of canal compromise.

\section{Methods}

Two hundred and forty-eight cases of spinal injuries at the thoracolumbar and lumbar levels were treated at this centre between January 1996 and January 1999. Of these, 61 cases had burst fractures. Patients with multiple level fractures, pathological fractures and those treated surgically were excluded from the study. The remaining 45 patients formed the basis of this study.

There were thirty-four patients with fractures in the thoracolumbar region and eleven patients with fractures in the lumbar region. The male to female ratio was $10: 1$. The mean age at the time of injury was 35.6 years (range 17-60 years).

The most common mechanism of injury was falling from a height $(96 \%)$ and the most common vertebra 
involved was $\mathrm{T}_{12}$ vertebra. Fourteen patients presented within $6 \mathrm{~h}$ following injury; 26 patients were admitted within $24 \mathrm{~h}$ whereas the rest were seen between $24-$ $40 \mathrm{~h}$ after the injury (mean $11.6 \mathrm{~h}$ ).

\section{Neurological evaluation}

After admission neurological examination was carried out every $2 \mathrm{~h}$ for $24 \mathrm{~h}$ in all patients. The neurological deficit noted after the return of the bulbocavernous reflex (end of the spinal shock) was considered as the initial neurological status. The neurological status was classified according to American Spinal Injury Association's modified Frankel's grading of traumatic paraplegia. ${ }^{9}$

\section{Radiological evaluation}

Antero-posterior and lateral roentgenograms and computerized tomographic scans were performed in all patients.

The least mid sagittal diameter of the spinal canal at the level of injury was measured. The normal mid sagittal diameter of the spinal canal was estimated by calculating the average of the corresponding measurements at the adjacent uninjured level above and below the injury. The percentage of the spinal canal compromise at presentation (a) was calculated using the formula of Hashimoto et $a l^{2}$ as shown below:

$$
\mathrm{a}=\left(\begin{array}{ll}
1 & \mathrm{x} / \mathrm{y}
\end{array}\right) \times 100
$$

where $\mathrm{a}=$ percentage of canal compromise,

$\mathrm{x}=$ mid -sagittal diameter of spinal canal at the level of injury

$y=$ average mid- sagittal diameter of the spinal canal.

\section{Treatment}

All 45 patients were treated non-operatively in the form of postural reduction, immobilization in polyethylene moulded body jacket and recumbency for 3 months. Associated injuries and complications were treated accordingly.

\section{Follow-up}

The neurological status was reassessed at regular intervals of 3 months. At the end of the first 3 months, the patients were made to sit and by the end of six months following injury they were mobilized. The final neurological evaluation was performed at the time of repeat CT scan.

CT scans were repeated in all cases after a minimum of 1 year follow up. The maximum follow up period was 2 years. The percentage of spinal canal narrowing at follow-up (b) was calculated with the above formula. The percentage of remodeling that had occurred was calculated using the formula:

$$
\left[\frac{a}{a}\right] \times 100
$$

where $\mathrm{a}=$ the spinal canal compromise at the time of injury

$\mathrm{b}=$ the spinal canal compromise at follow up

Analysis of variance was used to compute statistical differences at the 0.05 level of significance.

\section{Results}

\section{Neurological status}

The neurological status of the patients at admission and at the follow up is depicted in the Table 1 . Twenty-two patients $(58 \%)$ had incomplete neurological deficit, 11 (24\%) had complete neurological deficit and the remaining patients had no neurological deficit. Among patients with neurological deficit, in 11 patients no appreciable improvement in neurological status was noted. Among the patients who did improve neurologically, the median improvement was one grade in the Frankel's scale.

\section{Neurological impairment and canal compromise}

Table 2 shows the association between the neurological deficit and the extent of canal compromise at the time of admission. The mean spinal canal compromise in patients with neurologic deficit was $46.2 \%$ while in patients with no neurological deficit it was $36.3 \%$. There was no statistically significant difference between the severity of neurological deficit and the extent of canal compromise.

\section{Canal compromise and neurological recovery}

The mean percentage of spinal canal compromise in patients with neurological recovery was $46.1 \pm 20.9$ and $48.4 \pm 21.1$ in those with no recovery. This difference was not statistically significant.

\section{Neurological recovery and canal remodeling}

The mean percentage of the degree of canal remodeling in patients who recovered was $51.7 \pm 13.7$ and $46.1 \pm 11.0$ in patients who did not recover. This difference again was not statistically significant.

Table 1 Neurological status at admission and follow up

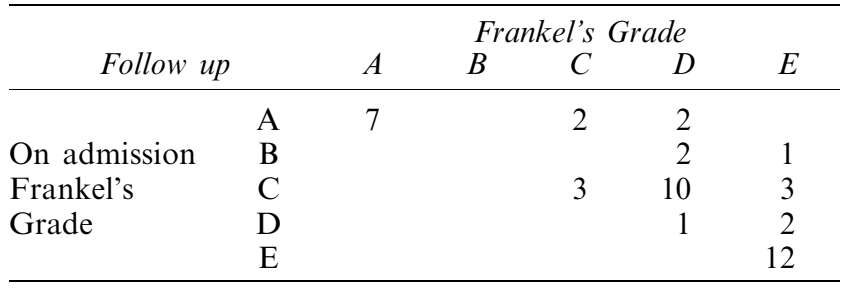


Table 2 The relationship between the neurological impairment at the time of admission and the extent of canal compromise

\begin{tabular}{lrcl}
\hline $\begin{array}{c}\text { Neurological Status } \\
\text { Grade }\end{array}$ & $\mathrm{n}$ & $\begin{array}{c}\text { Canal Compromise }(\%) \\
\text { Mean } \pm \text { s.d. }\end{array}$ & Significance \\
\hline $\mathrm{A}$ & 11 & $44.3 \pm 18.6$ & \\
$\mathrm{~B}$ & 3 & $38.6 \pm 25.6$ & \\
$\mathrm{C}$ & 16 & $48.6 \pm 19.9$ & $\mathrm{NS}$ \\
$\mathrm{D}$ & 3 & $51.3 \pm 35.9$ & \\
$\mathrm{E}$ & 12 & $36.3 \pm 19.3$ & \\
\hline
\end{tabular}

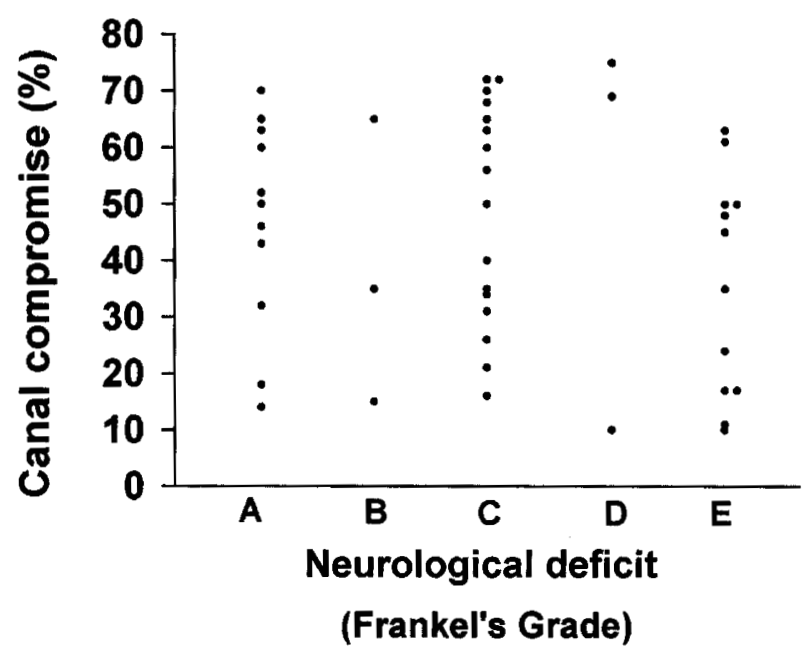

Figure 1 The relationship between neurological deficit and initial canal compromise

\section{Discussion}

Neurologic injury has been reported to occur in $30 \%-$ $60 \%$ of the patients with thoracolumbar burst fractures. ${ }^{10}$ Various authors have reported a relationship between the degree of canal compromise and the extent of neurologic deficit. ${ }^{1,2,6,10-12}$ Others have noted that there is no correlation between the initial neurological impairment and the degree of spinal canal narrowing. ${ }^{8,13-15}$

In the present study, there was no statistically significant correlation between the degree of canal encroachment and initial neurologic deficit. A patient with $75 \%$ canal compromise at $\mathrm{T}_{12}$ level was in Frankel D group whereas a patient with mere $14 \%$ canal compromise at $T_{12}$ level had complete neurologic deficit (Figure 1).

There was also no correlation between the neurological recovery and initial canal compromise. This is similar to the views of El Masry et $a l^{6,13}$ who are of the opinion that there is no correlation between the degree of canal encroachment, initial degree of neurological impairment or degree of neurological recovery. However Li-Yang Dai ${ }^{16}$ found the recovery rate to be significantly related to the first examination stenotic ratio.
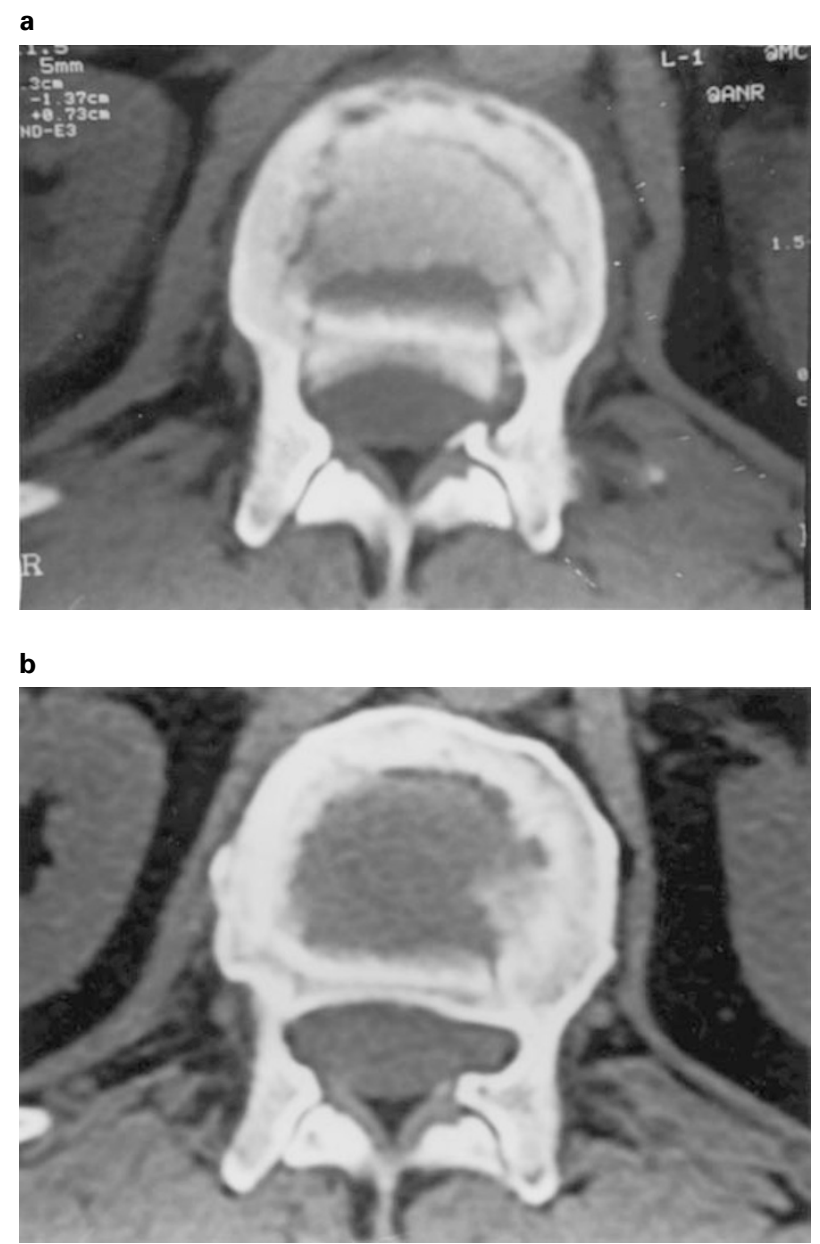

Figure 2 (A) CT scan of a 52 year old man with a burst fracture at L1 showing canal compromise of $69 \%$. He had neurological deficit of Frankel grade 'D' (B) CT scan at 1 year follow-up showing $29 \%$ canal compromise (remodeling of $58 \%$ ). He recovered to Frankel grade ' $E$ '

It is generally accepted that patients with incomplete injury to the cord or the cauda equina initially have better chances of neurological improvement than patients who initially have complete cord injury. ${ }^{2,12,17}$ Our study also demonstrated this phenomenon. Of 11 patients with complete neurological deficit, only four recovered, while out of 22 patients with incomplete deficit, 18 improved upon their pretreatment Frankel grade. These findings support the view of Rosenberg et $a l^{18}$ that the initial impact to the spinal cord determines the future neurological outcome regardless of the spinal segment injured.

Limb et $a l^{19}$ suggest that the static image of the canal obtained by the computerized tomography scans hours or days after the injury does not necessarily reflect the displacement at the time of injury, which is what determines the initial neurological insult. The degree of spinal canal narrowing reflects the final resting position of the vertebral body fragments after the trauma. This would explain why the present study 
a

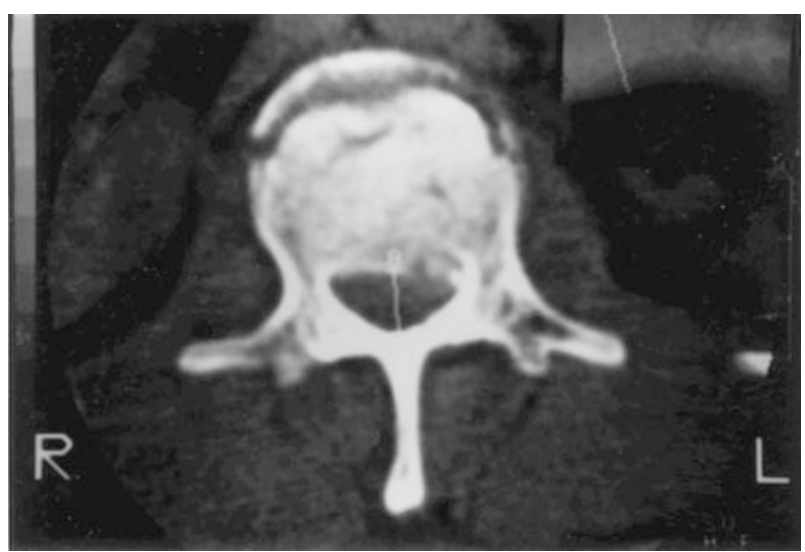

b

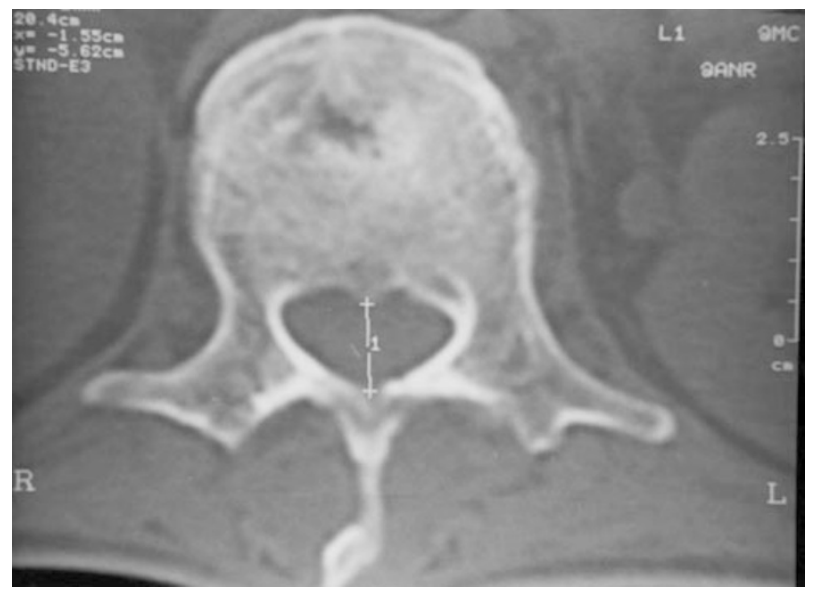

Figure 3 (A) CT scan of a 47 year old male with a burst fracture at L1 showing canal compromise of $32 \%$. He had Frankel grade 'A' paraplegia. (B) CT scan at 1 year followup showing $20 \%$ canal compromise (remodeling of $37 \%$ ). $\mathrm{He}$ did not show any recovery

failed to show any association between the extent of canal compromise and the extent of neurological deficit (Figure 1).

Several studies have shown that the spinal canal remodels as the time progresses. ${ }^{16,20-24}$ de Klerk et $a l^{24}$ observed that the process of remodeling usually takes place during the first year after injury; after this period, there is little further remodeling. It is for this reason that we analyzed the follow-up canal compromise at 1 year. The percentage of remodeling noted in this study ranged from $28 \%$ to $100 \%$. Canal remodeling was seen in all patients irrespective of the neurological involvement. However the extent of canal remodeling was not related to the degree of neurological recovery (Figures 2a,b and 3a,b).

In the light of our results the rationale of decompression of the spinal canal to remove any retropulsed bony fragments with a hope of improving the neurological status advocated by some surgeons ${ }^{25,26}$ seems questionable.

\section{Conclusion}

We conclude that in burst fractures of the thoracolumbar and lumbar spine there is no correlation between the neurologic deficit or the recovery pattern with the extent of canal compromise. Like other bones, fractured vertebrae also undergo substantial remodeling so that the size and shape of the spinal canal improves with time. However this remodeling does not have a bearing on neurological recovery.

\section{Acknowledgements}

The authors wish to thank Dr Sreekumaran Nair, Associate Professor, Community Medicine, for contributing the statistical analysis of the data. They are also thankful to Professor Benjamin Joseph, Manipal, for his valuable suggestions to improve the manuscript.

\section{References}

1 Denis F. Spinal instability as defined by the three-column spine concept in acute spinal trauma. Clin Orthop 1984; 189: $65-76$.

2 Hashimoto T, Kaneda K, Abumi K. Relationship between traumatic spinal canal stenosis and neurologic deficits in thoracolumbar burst fractures. Spine 1988; 13: $1268-1272$.

3 Mumford J, Weinstein JN, Spratt KF, Goel VK. Thoracolumbar burst fractures: The clinical efficacy and outcome of non-operative management. Spine 1993; 18: $955-970$.

4 Knight RQ, Stomelli DP, Chan DPK. Comparison of operative versus non-operative treatment of lumbar burst fractures. Clin Orthop 1993; 293: $112-121$.

5 Mohanty SP, Hammidreza K, Shahrokh E. A comparative analysis of operative and non-operative management of thoracic and lumbar spine injuries. Indian Journal of Orthopaedics 1999; 33: 267-270.

6 El Masry WS, Short DJ. Current Concepts: Spinal Injuries and rehabilitation. Current Opinion in Neurology 1997; 10: $484-492$.

7 Lemons V, Wagner F, Montesano P. Management of thoracolumbar fractures with accompanying neurological injury. Neurosurgery 1992; 30: 667-671.

8 Shuman WP et al. Thoracolumbar burst fractures: CT dimensions of the spinal canal relative to postsurgical improvement. AJR 1985; 145: $337-341$.

9 Maynard FM et al. International standards for neurological and functional classification of spinal cord injury. Spinal Cord 1997; 35: 266-274.

10 Trafton PG, Boyd CA. Computed tomography of thoracic and lumbar spine injuries. J Trauma 1984; 24: $506-515$.

11 Gertzbein SD. Multicentre spine fracture study. Spine 1992; 17: $528-540$.

$12 \mathrm{Kim}$ NH, Lee HM, Chan IM. Neurologic injury and recovery in patients with burst fractures of the thoracolumbar spine. Spine 1999; 24: 290-294. 
13 El Masry WS, Katoh S, Khan A. Reflections on the neurological significance of bony canal encroachment following traumatic injury of the spine in patients with Fraenkel C, D and E presentation. J Neurotrauma 1993; 10 (Suppl.): 70.

14 Herndon WA, Galloway D. Neurological return versus cross-sectional canal area in incomplete thoracolumbar spinal cord injuries. J Trauma 1988; 28: 680-683.

15 Starr JK, Hanley EN. Junctional burst fractures. Spine 1992; 17: $551-557$.

16 Li-Yang Dai. Remodeling of the spinal canal after thoracolumbar burst fractures. Clin Orthop 2001; 382: $119-123$.

17 Katoh S, El Masry WS. Motor recovery of patients presenting with motor paralysis and sensory sparing following cervical spinal cord injury. Paraplegia 1995; 33: $506-509$.

18 Rosenberg $\mathrm{N}$ et al. Neurological deficit in a consecutive series of vertebral fracture patients with bony fragments within spinal canal. Spinal Cord 1997; 35: $92-95$.

19 Limb D, Shaw DL, Dickson RA. Neurological injury in thoracolumbar burst fractures. J Bone Joint Surg ( $\mathrm{Br}$ ) 1995; 77-B: $774-777$.
20 Fidler MW. Remodeling of the spinal canal after burst fracture. A prospective study of 2 cases. J Bone Joint Surg (Br) 1988; 70B: $730-732$.

21 Johnsson $\mathrm{R}$ et al. Spinal canal remodelling after thoracolumbar fractures with intraspinal bone fragments; 17 cases followed 1-4 years. Acta Orthop Scand 1991; 62: $125-127$

22 Krompinger WJ, Frekerickson BE, Mino DE, Yuan HA. Conservative treatment of fractures of the thoracic and lumbar spine. Orthop Clin North Am 1986; 17: 161-170.

23 Kinoshita $\mathrm{H}$ et al. Conservative treatment of burst fractures of the thoracolumbar and lumbar spine. Paraplegia 1993; 31: 58-67.

24 de Klerk LWL et al. Spontaneous remodeling of the Spinal canal after conservative management of thoracolumbar burst fractures. Spine 1998; 23: $1057-1060$.

25 Bradford DS, McBride G. Surgical management of thoracolumbar spine fractures with incomplete neurologic deficits. Clin Orthop 1987; 218: $201-216$.

26 McAfee PG, Bohlman HH, Yuan HA. Anterior decompression of traumatic thoracolumbar fractures with incomplete neurological deficit using a retroperitoneal approach. J Bone Joint Surg (Am) 1985; 67: 89-104. 